\title{
Predicting waist circumference from body mass index
}

\author{
Samuel R Bozeman ${ }^{1 \dagger}$, David C Hoaglin ${ }^{2 \dagger}$, Tanya M Burton ${ }^{3+}$, Chris L Pashos ${ }^{4 *}{ }^{4}$, Rami H Ben-Joseph ${ }^{5}$ and \\ Christopher S Hollenbeak ${ }^{6+}$
}

\begin{abstract}
Background: Being overweight or obese increases risk for cardiometabolic disorders. Although both body mass index (BMI) and waist circumference (WC) measure the level of overweight and obesity, WC may be more important because of its closer relationship to total body fat. Because WC is typically not assessed in clinical practice, this study sought to develop and verify a model to predict WC from BMI and demographic data, and to use the predicted WC to assess cardiometabolic risk.
\end{abstract}

Methods: Data were obtained from the Third National Health and Nutrition Examination Survey (NHANES) and the Atherosclerosis Risk in Communities Study (ARIC). We developed linear regression models for men and women using NHANES data, fitting waist circumference as a function of BMI. For validation, those regressions were applied to ARIC data, assigning a predicted WC to each individual. We used the predicted WC to assess abdominal obesity and cardiometabolic risk.

Results: The model correctly classified $88.4 \%$ of NHANES subjects with respect to abdominal obesity. Median differences between actual and predicted WC were $-0.07 \mathrm{~cm}$ for men and $0.11 \mathrm{~cm}$ for women. In ARIC, the model closely estimated the observed WC (median difference: $-0.34 \mathrm{~cm}$ for men, $+3.94 \mathrm{~cm}$ for women), correctly classifying $86.1 \%$ of ARIC subjects with respect to abdominal obesity and $91.5 \%$ to $99.5 \%$ as to cardiometabolic risk. The model is generalizable to Caucasian and African-American adult populations because it was constructed from data on a large, population-based sample of men and women in the United States, and then validated in a population with a larger representation of African-Americans.

Conclusions: The model accurately estimates WC and identifies cardiometabolic risk. It should be useful for health care practitioners and public health officials who wish to identify individuals and populations at risk for cardiometabolic disease when WC data are unavailable.

\section{Background}

Body mass index (BMI), defined as weight in kilograms divided by the square of height in meters, has long been an important measure of excess body fat, and a high BMI is a well-recognized risk factor for cardiometabolic disorders. BMI is easily obtained and commonly assessed in clinical settings, and most current standards for overweight $\left(\mathrm{BMI} \geq 25 \mathrm{~kg} / \mathrm{m}^{2}\right)$ and obesity $\left(\mathrm{BMI} \geq 30 \mathrm{~kg} / \mathrm{m}^{2}\right)$ are based on BMI [1]. Current World Health Organization guidelines for cardiometabolic risk employ these thresholds [2]. Recent research, however, suggests that the

\footnotetext{
* Correspondence: chris.pashos@unitedbiosource.com

${ }^{\dagger}$ Equal contributors

${ }^{4}$ United BioSource Corporation, Lexington, MA, USA

Full list of author information is available at the end of the article
}

distribution of body fat, for which BMI does not account, is a more important indicator of cardiovascular risk [3]. In particular, increased visceral fat has been shown to be an important risk factor for cardiovascular disease and diabetes, among other metabolic disorders [4-6]. An indicator of visceral fat, waist circumference (WC), is more sensitive to the distribution of body fat than is BMI [7], and therefore a better surrogate measure of android adiposity [8]. Previous work has attempted to define the link between the two measures by identifying BMI ranges that are equivalent in risk of cardiovascular events to WC ranges in current guidelines [9]. Current definitions of cardiometabolic risk factors, including guidelines issued by the National Cholesterol Education Program Adult Treatment Panel III (NCEP-ATP III) and International Diabetes

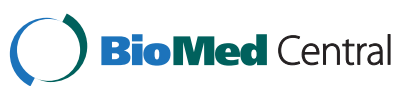

(C) 2012 Bozeman et al.; licensee BioMed Central Ltd. This is an Open Access article distributed under the terms of the Creative Commons Attribution License (http://creativecommons.org/licenses/by/2.0), which permits unrestricted use, distribution, and reproduction in any medium, provided the original work is properly cited. 
Federation (IDF) for metabolic syndrome classification, include WC [10]. Previous research has demonstrated the prevalence of these conditions in well-characterized U.S. populations [11,12]. However, given the historical use of BMI in clinical practice, WC is not as widely available in established clinical databases. We sought to determine how closely WC could be predicted from BMI and two or three important demographic covariates - gender, age, and (optionally) race and ethnicity - as a basis for imputing WC when only BMI or weight and height are available, and to use the predicted WC to assess cardiometabolic risk.

\section{Methods}

\section{Data}

Following institutional review board approval by the Abt Associates Institutional Review Board, de-identified data were obtained for this study from two large studies: (1) the Third National Health and Nutrition Examination Survey (NHANES) 2001-2002 cohort and (2) the Atherosclerosis Risk in Communities Study (ARIC). The analytical model was built using data from NHANES, a national probability sample of the United States population collecting information on health and nutritional status [13]. Files contain both WC and BMI measurements, as well as demographic characteristics data, including age, gender, race, and ethnicity. The NHANES 2001-2002 data set contains data for 11,039 persons. We included individuals 18 years of age or older with no missing data on WC and BMI and excluded individuals with BMI $>40 \mathrm{~kg} / \mathrm{m}^{2}$, which yielded a study sample of 4,641 adults.

To validate the gender-specific models, we applied them to data from ARIC, a prospective study of community sites in Maryland, Mississippi, Missouri, and North Carolina that examined risk factors and the natural history of atherosclerosis and cardiovascular disease in an ethnically diverse population [14]. A cohort of nearly 16,000 was examined at baseline (1987) and re-examined four times at 3-year intervals. Examinations included extensive laboratory tests and anthropometric assessments. In addition to periodic medical examinations, study staff conducted yearly follow-up telephone interviews to update the health status of each participant. Analyses presented here use data collected between 1996 and 1998 at Examination 4, which included 11,596 study participants.

\section{Model for WC}

An initial model expressed the regression of WC on BMI in the following form:

$$
\begin{aligned}
W C_{i}=b_{0} & +b_{1} B M I_{i}+b_{2} A G E_{i}+b_{3} B L A C K_{i} \\
& +b_{4} H_{S S P_{i}}+e_{i}
\end{aligned}
$$

where $i$ indexes individuals, $W C_{i}$ is waist circumference for individual $i, B M I_{i}$ is body mass index, $A G E_{i}$ is current age (in years), $B L A C K_{i}$ is an indicator for African-American, $H I S P_{i}$ is an indicator for Hispanic ethnicity, and $e_{i}$ is the residual. Because the relation of $\mathrm{WC}$ to $\mathrm{BMI}$ involved nonlinearity when $\mathrm{BMI}>40 \mathrm{~kg} / \mathrm{m}^{2}$ for both sexes, we based the models on data from individuals with $\mathrm{BMI} \leq 40 \mathrm{~kg} / \mathrm{m}^{2}$. (For individuals with $\mathrm{BMI}>40 \mathrm{~kg} / \mathrm{m}^{2}$ it is unlikely that a value of WC, either measured or predicted, will be needed as a guide to treatment.) An exploratory analysis, fitting a separate constant for each 2-year interval of age, revealed that the contribution of age to the model differed between men and women. For men the contribution was well summarized by a linear term in age, as in Equation 1. For women the pattern was better summarized by using one constant for age $<35$ years and a separate intercept and slope for age $\geq 35$ years. Thus, the model for women was

$$
\begin{aligned}
W C_{i}= & c_{0}+c_{1} B M I_{i}+c_{2} I\left\{A G E_{i} \geq 35\right\}+c_{3} A G E_{i} \\
& \times I\left\{A G E_{i} \geq 35\right\}+c_{4} B_{L A C K_{i}}+c_{5} H_{S P P_{i}}+e_{i}
\end{aligned}
$$

where $I\{B\}$ is an indicator function: $I\{B\}=1$ when $B$ is true and 0 otherwise. The contributions of race and ethnicity were adequately accounted for by those indicator variables; separate models were not necessary. Because NHANES used a complex sample design and oversampled certain segments of the population, the regressions took into account the sample design and survey weights.

We developed two additional models (one for men and one for women) omitting the $B L A C K_{i}$ and $H I S P_{i}$ variables. The results were essentially the same, and are available upon request.

\section{Validation}

The linear regression models derived from the NHANES data yielded a predicted waist circumference for every individual in the ARIC dataset with $\mathrm{BMI} \leq 40 \mathrm{~kg} / \mathrm{m}^{2}$ and $A G E<70$ years. We applied the restriction on $A G E$ because the variable had been recoded to 70 for individuals who should have had $A G E=71,72$, or 73 years; the correct values were not available. In addition, we recalculated each individual's BMI from the reported values of weight and height after we discovered that, for a small percentage of individuals, the reported BMI differed from the calculated BMI by a substantial amount. We computed the difference between observed and predicted waist circumference for each individual, and used the mean and various percentiles to summarize those differences. Examination of the distributions of differences from the two models revealed a moderate number of large values, which we investigated further.

Definitions of the seven cardiometabolic risk factor sets are presented in Table 1 [10]. We assessed membership in each defined risk factor set using the actual and 
predicted waist circumference values for each individual. We computed sensitivity, specificity, and positive predictive value (PPV) using the predicted waist circumference as a "screening test" against the measured waist circumference as the "gold standard" for membership.

\section{Results}

Characteristics of persons in the NHANES 2001-2002 sample used to develop the model are representative of the U.S. population, with an average age near 44 years, predominantly white, and with an average BMI in the overweight but not obese range (Table 2). Coefficients for the models are presented in Table 3. To estimate $\mathrm{WC}$, the coefficients and the values of the predictors are substituted into the equations. For example, the predicted WC of a 40-year-old white non-Hispanic man with a BMI of $35 \mathrm{~kg} / \mathrm{m}^{2}$ is computed as: $22.61306+2.520738 *(35)+0.1583812^{*}(40)$ $-3.703501^{*}(0)-1.736731^{*}(0)=117.2 \mathrm{~cm}$. The predicted WC for a 50-year-old black non-Hispanic woman with a BMI of $28 \mathrm{~kg} / \mathrm{m}^{2}$ is computed as $28.81919+2.218007^{*}(28)-3.688953^{*}(1)+0.125975 *(50)$ $(1)-0.6570163^{*}(1)+0.1818819^{*}(0)=92.9 \mathrm{~cm}$.
Table 2 Characteristics of NHANES 2001-2 sample

\begin{tabular}{llccc}
\hline & \multicolumn{2}{l}{ Men $(\mathbf{N}=\mathbf{2 , 2 4 6})$} & \multicolumn{2}{c}{ Women $(\mathbf{N}=\mathbf{2 , 3 9 5})$} \\
\hline Age & Mean & Std. Error & Mean & Std. Error \\
Race/Ethnicity & 43.95 & 0.559 & 44.64 & 0.531 \\
White & $76.6 \%$ & & & \\
Black & $10.1 \%$ & & $76.1 \%$ & \\
Hispanic & $13.3 \%$ & & $11.1 \%$ & \\
Body Fat & & & $12.8 \%$ & \\
WC & 97.4 & 0.295 & 90.5 & 0.384 \\
BMl & 27.2 & 0.088 & 26.9 & 0.143 \\
Overweight & $43.5 \%$ & & $30.3 \%$ & \\
Obese $^{\text {b }}$ & $23.9 \%$ & & $28.2 \%$ & \\
\hline
\end{tabular}

${ }^{\mathrm{a}} \mathrm{BMI} \geq 25$.

${ }^{b} \mathrm{BMI} \geq 30$

For men, the predicted WC is reasonably close to the actual WC, and for women it is somewhat less close than for men. The median difference (actual WC minus predicted WC) for men is $-0.07 \mathrm{~cm}$, and the middle half of the differences extends from $-3.14 \mathrm{~cm}$ to $+3.00 \mathrm{~cm}$. For women the median difference is $0.11 \mathrm{~cm}$, and the

Table 1 Specifications of Cardiometabolic Risk Factor Sets

\begin{tabular}{|c|c|c|c|c|c|c|c|}
\hline & $\begin{array}{l}\text { Metabolic Syndrome } \\
\text { NCEP-ATP III }\end{array}$ & $\begin{array}{l}\text { Abdominal } \\
\text { Obesity } 1 \text { (AO) }\end{array}$ & AO + Diabetes & AO + Dyslipidemia & $\begin{array}{l}\text { AO + Diabetes + } \\
\text { Dyslipidemia }\end{array}$ & $\begin{array}{l}\text { Metabolic Syndrome } \\
\text { IDF }^{\mathrm{a}}\end{array}$ & $\begin{array}{l}\text { Abdominal } \\
\text { Obesity } 2\end{array}$ \\
\hline & $\begin{array}{l}\geq 3 \text { of the following } \\
\text { risk factors }\end{array}$ & High WC & High WC + diabetes & $\begin{array}{l}\text { High WC + high } \\
\text { TG or low HDL }\end{array}$ & $\begin{array}{l}\text { High WC + } \\
\text { diabetes + high } \\
\text { TG or low HDL }\end{array}$ & $\begin{array}{l}\text { High WC }+2 \text { of the } \\
\text { other } 4 \text { risk factors }\end{array}$ & High WC \\
\hline \multirow[t]{2}{*}{ WC } & Men $\geq 102 \mathrm{~cm}$ & Men $\geq 102 \mathrm{~cm}$ & Men $\geq 102 \mathrm{~cm}$ & Men $\geq 102 \mathrm{~cm}$ & Men $\geq 102 \mathrm{~cm}$ & Men $\geq 94 \mathrm{~cm}^{\mathrm{b}}$ & Men $\geq 94 \mathrm{~cm}^{\mathrm{b}}$ \\
\hline & Women $\geq 88 \mathrm{~cm}$ & Women $\geq 88 \mathrm{~cm}$ & Women $\geq 88 \mathrm{~cm}$ & Women $\geq 88 \mathrm{~cm}$ & Women $\geq 88 \mathrm{~cm}$ & Women $\geq 80 \mathrm{~cm}^{\mathrm{b}}$ & Women $\geq 80 \mathrm{~cm}^{\mathrm{b}}$ \\
\hline $\mathrm{TG}$ & $\geq 150 \mathrm{mg} / \mathrm{dL}$ & NA & NA & $\geq 150 \mathrm{mg} / \mathrm{dL}$ & $\geq 150 \mathrm{mg} / \mathrm{dL}$ & $\begin{array}{l}\geq 150 \mathrm{mg} / \mathrm{dL} \text {, or } \\
\text { on treatment for } \\
\text { high TG }\end{array}$ & NA \\
\hline \multirow[t]{3}{*}{$\mathrm{HDL}$} & Men $<40 \mathrm{mg} / \mathrm{dL}$ & NA & NA & Men $<40$ mg/dL & Men < 40 mg/dL & Men $<40$ mg/dL & NA \\
\hline & Women < 50 mg/dL & & & Women $<50 \mathrm{mg} / \mathrm{dL}$ & $\begin{array}{l}\text { Women }<50 \\
\mathrm{mg} / \mathrm{dL}\end{array}$ & $\begin{array}{l}\text { Women }<50 \\
\mathrm{mg} / \mathrm{dL} \text { or }\end{array}$ & \\
\hline & & & & & & $\begin{array}{l}\text { on treatment for } \\
\text { low HDL }\end{array}$ & \\
\hline \multirow[t]{4}{*}{$\mathrm{BP}$} & $\mathrm{SBP} \geq 130 \mathrm{~mm} \mathrm{Hg}$ or & NA & NA & NA & NA & $\mathrm{SBP} \geq 130 \mathrm{~mm} \mathrm{Hg}$ or & NA \\
\hline & $\mathrm{DBP} \geq 85 \mathrm{~mm} \mathrm{Hg}$ or & & & & & $\mathrm{DBP} \geq 85 \mathrm{~mm} \mathrm{Hg}$ or & \\
\hline & $\begin{array}{l}\text { current use of } \\
\text { anti-hypertensive } \\
\text { medication }\end{array}$ & & & & & $\begin{array}{l}\text { current use of } \\
\text { anti-hypertensive } \\
\text { medication }\end{array}$ & \\
\hline & & & & & & (Same as for NCEP) & \\
\hline \multirow[t]{2}{*}{ FPG } & $\geq 100 \mathrm{mg} / \mathrm{dL}$ or & NA & $\geq 126 \mathrm{mg} / \mathrm{dL}$ or & NA & $\geq 126 \mathrm{mg} / \mathrm{dL}$ or & $\geq 100 \mathrm{mg} / \mathrm{dL}$ or & NA \\
\hline & $\begin{array}{l}\text { use of diabetes } \\
\text { medication }\end{array}$ & & $\begin{array}{l}\text { use of diabetes } \\
\text { medication }\end{array}$ & & $\begin{array}{l}\text { use of diabetes } \\
\text { medication }\end{array}$ & $\begin{array}{l}\text { previously diagnosed } \\
\text { type } 2 \text { diabetes }\end{array}$ & NA \\
\hline
\end{tabular}

WC waist circumference, TG triglycerides, HDL high-density lipoprotein, BP blood pressure, FPG fasting plasma glucose, NCEP National Cholesterol Education Program, ATP III Adult Treatment Panel III.

${ }^{a}$ Ford, E. S. Prevalence of the metabolic syndrome defined by the International Diabetes Federation among adults in the U.S. Diabetes Care 2005, 28:2745-2749.

${ }^{b}$ For White and African American subjects. Refer to ${ }^{a}$ Ford, E.S. article for other ethnic group-specific thresholds including for Mexican-American subjects. 
Table 3 Models for predicting waist circumference from BMI

\begin{tabular}{|c|c|c|c|c|c|c|}
\hline & \multicolumn{3}{|c|}{ Men $(\mathrm{N}=2,395)$} & \multicolumn{3}{|c|}{ Women $(N=2,246)$} \\
\hline & Coefficient & Std. Error & P-Value & Coefficient & Std. Error & P-Value \\
\hline Constant & 22.61306 & 0.8792 & $<0.0001$ & 28.81919 & 0.8011 & $<0.0001$ \\
\hline Age & 0.1583812 & 0.0049 & $<0.0001$ & - & - & - \\
\hline I $\{$ Age $\geq 35\}$ & - & - & - & -3.688953 & 0.8308 & $<0.0001$ \\
\hline Age $\times \mid\{$ Age $\geq 35\}$ & - & - & - & 0.125975 & 0.0118 & $<0.0001$ \\
\hline $\mathrm{BMI}$ & 2.520738 & 0.0338 & $<0.0001$ & 2.218007 & 0.0318 & $<0.0001$ \\
\hline Black & -3.703501 & 0.3194 & $<0.0001$ & -0.6570163 & 0.6730 & 0.344 \\
\hline Hispanic & -1.736731 & 0.4848 & 0.003 & 0.1818819 & 0.6729 & 0.79 \\
\hline
\end{tabular}

quartiles are at $-3.84 \mathrm{~cm}$ and $+3.81 \mathrm{~cm}$. To maximize comparability with ARIC, Figure 1 shows boxplots of the difference for men and women NHANES participants in the age range of 54 to 69 years. In this display the box covers the middle half of the data, from the $25^{\text {th }}$ percentile to the $75^{\text {th }}$ percentile, and the line across it shows the location of the median. Beyond lower and upper cutoffs (1.5 times the interquartile range below the $25^{\text {th }}$ percentile and above the $75^{\text {th }}$ percentile, respectively), data values are shown individually, and the "whiskers" indicate the range of the remaining data. For the 462 men in this age range, the median difference is $-0.15 \mathrm{~cm}$, and the quartiles are at $-3.22 \mathrm{~cm}$ and $+3.21 \mathrm{~cm}$. Three men had differences that were sizable enough to be shown at the ends of the boxplot (one negative and two positive). For the corresponding 458 women, the median difference is $+0.47 \mathrm{~cm}$, and the quartiles are at $-3.66 \mathrm{~cm}$ and $+4.86 \mathrm{~cm}$. Eight women's differences are beyond the cutoffs (two high and six low). At the median the model for women underpredicts WC slightly, and the differences for women are considerably more variable than those for men.

Table 4 shows the characteristics of persons in the ARIC population used in validating the model. The

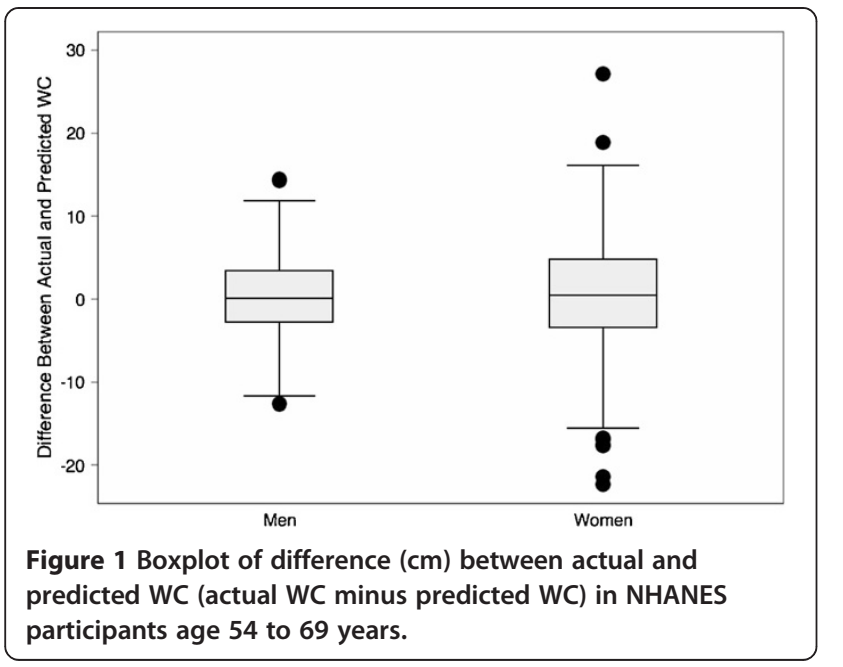

average age of 61 is 17 years older than the NHANES population. (Participants in ARIC ranged in age from 45 to 64 years at Examination 1, so the range at Examination 4 would have been, with few exceptions, 54 to 73 years.) The ARIC participants contained more women than men (56.6\% vs $43.4 \%$ ), and more (especially women) were African-American. The population is predominantly white. The mean BMI and WC values are slightly higher for ARIC in men and women, with an average BMI in the overweight but not obese range.

As seen in Figure 2, for the ARIC study participants as a whole, the predicted WC is also reasonably close to the actual WC. For men the median difference is $-0.34 \mathrm{~cm}$, and the quartiles are $-3.49 \mathrm{~cm}$ and $+2.74 \mathrm{~cm}$. For women the median difference, $+3.94 \mathrm{~cm}$, corresponds to underestimation of WC; the quartiles, $-0.79 \mathrm{~cm}$ and $+8.47 \mathrm{~cm}$, yield an interquartile range of $9.26 \mathrm{~cm}$, roughly 1.5 times the interquartile range for men. Of the 3,806 men, 33 had differences that were outside the cutoffs of the boxplot (12 negative and 21 positive). Only the most extreme of these, however,

Table 4 Characteristics of ARIC sample at Examination 4

\begin{tabular}{|c|c|c|c|c|}
\hline & \multicolumn{2}{|c|}{ Men $(\mathrm{N}=3,806)$} & \multicolumn{2}{|c|}{ Women $(\mathrm{N}=4,967)$} \\
\hline & Mean & Std. Dev & Mean & Std. Dev \\
\hline Age (Years) & 61 & 4.5 & 61 & 4.5 \\
\hline \multicolumn{5}{|l|}{ Race/Ethnicity } \\
\hline White & $81 \%$ & & $75 \%$ & \\
\hline Black & $19 \%$ & & $25 \%$ & \\
\hline Hispanic & $0 \%$ & & $0 \%$ & \\
\hline \multicolumn{5}{|l|}{ Body Fat } \\
\hline WC $(\mathrm{cm})$ & 103 & 10.7 & 99 & 13.9 \\
\hline Derived BMI $\left(\mathrm{kg} / \mathrm{m}^{2}\right)$ & 28.4 & 4.0 & 28.2 & 5.0 \\
\hline Height (cm) & 176 & 6.5 & 162 & 5.9 \\
\hline Weight (lbs) & 194 & 30.7 & 163 & 30.9 \\
\hline Overweight $^{a}$ & $80 \%$ & & $71 \%$ & \\
\hline Obese $^{b}$ & $33 \%$ & & $35 \%$ & \\
\hline
\end{tabular}

B $B M 1 \geq 2$ 


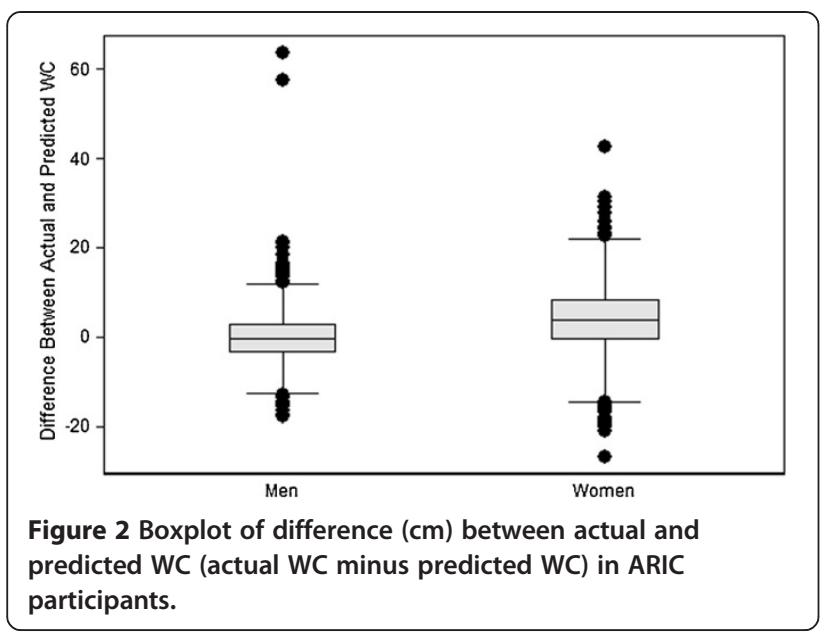

would normally be regarded as outliers. The largest two differences, 63.6 and 57.4, were caused by errors in the ARIC data, as we discovered from relating their height, weight, and BMI on Examination 4 to their height and weight on the previous examinations. Of the 4,967 women, 37 had differences beyond the cutoffs (23 negative and 14 positive). The largest positive and negative differences reflected problems in the data. Aside from participants with apparently misrecorded data, those with extreme differences seemed to have combinations of height, weight, and WC that simply were not well fitted by the models. We also noticed that, of the 37 women with extreme residuals, 20 were black non-Hispanic. The similarity between Figure 2 and Figure 1 indicates that, in the absence of problems in the data, the models performed nearly as well in predicting WC for individuals in ARIC as they did for individuals in NHANES.

The difference between actual and predicted WC, however, is not uniform over the range of WC. In both
NHANES and ARIC and for both men and women, the models tend to overpredict when WC is small and underpredict when WC is large. Among men in both databases overprediction is noticeable (median 2 to $3 \mathrm{~cm}$ in WC intervals of width $5 \mathrm{~cm}$ ) for $\mathrm{WC}<95 \mathrm{~cm}$. A similar degree of underprediction occurs for men in NHANES with $W C \geq 115 \mathrm{~cm}$ and for men in ARIC with $\mathrm{WC} \geq 125 \mathrm{~cm}$. Among women in both databases the pattern was substantially stronger: overprediction of 3 to $5 \mathrm{~cm}$ (median) for $\mathrm{WC}<85 \mathrm{~cm}$, underprediction of around 5 to $7 \mathrm{~cm}$ (median) for $\mathrm{WC} \geq 115 \mathrm{~cm}$ in NHANES, and underprediction increasing steadily in ARIC from $3 \mathrm{~cm}$ (median) for $90 \mathrm{~cm} \leq W C \leq 94 \mathrm{~cm}$ to $9 \mathrm{~cm}$ (median) for $120 \mathrm{~cm} \leq \mathrm{WC} \leq 124 \mathrm{~cm}$. These patterns affect membership in the risk factor sets, discussed below.

Tables 5 and 6 present the results of using the predicted WC value to define membership in the seven cardiometabolic risk factor sets for women and men, respectively. For every risk factor set, the WC prediction model is slightly more successful (i.e., a higher positive predictive value and a higher proportion correctly identified as belonging to a particular risk factor set) for women than for men. For women, the proportion correctly identified using the predicted WC was $93.2 \%$ or higher for all sets except for the higher abdominal obesity threshold $(\geq 88 \mathrm{~cm})$ alone, where the proportion correctly identified was $86.8 \%$. The misclassified individuals (13\%) were twice as likely to be false negatives (i.e., incorrectly classified as not obese) as opposed to false positives. For this risk factor set, both specificity (correctly identifying non-membership for those who are non-members $-82.6 \%$ ) and sensitivity (correctly identifying membership for those who are members $-88.0 \%$ ) were low. For the risk factor sets excluding metabolic syndrome, the proportion correctly identified increases as the number of defining criteria increases, with $99.5 \%$

Table 5 Risk Factor Set Membership from Predicted WC in ARIC Women; BMI $\leq$ 40; Age < 70. ( $=$ 4967)

\begin{tabular}{lccccc}
\hline Risk Factor Set & $\begin{array}{l}\text { Observed proportion } \\
(\mathbf{N}) \text { in risk set }\end{array}$ & $\begin{array}{l}\text { Positive Predictive } \\
\text { Value }\end{array}$ & Sensitivity & $\begin{array}{c}\text { Specificity } \\
\text { Proportion correctly } \\
\text { predicted }\end{array}$ \\
\hline NCEP-ATP III Metabolic Syndrome & $50.2 \%(2495)$ & $98.1 \%$ & $95.4 \%$ & $98.2 \%$ & $96.8 \%$ \\
IDF Metabolic Syndrome & $55.2 \%(2744)$ & $98.7 \%$ & $98.7 \%$ & $98.3 \%$ & $98.5 \%$ \\
Abdominal Obesity1 (AO1) & $76.4 \%(3795)$ & $94.2 \%$ & $88.0 \%$ & $82.6 \%$ & $86.8 \%$ \\
AO1 and DM & $13.6 \%(675)$ & $98.8 \%$ & $95.3 \%$ & $99.8 \%$ & $99.2 \%$ \\
AO1 and Dyslipidemia & $45.2 \%(2243)$ & $96.9 \%$ & $90.7 \%$ & $97.6 \%$ & $94.5 \%$ \\
AO1, DM and Dyslipidemia & $9.6 \%(479)$ & $98.9 \%$ & $96.0 \%$ & $99.9 \%$ & $99.5 \%$ \\
Abdominal Obesity 2 & $91.8 \%(4560)$ & $95.7 \%$ & $97.0 \%$ & $51.4 \%$ & $93.2 \%$ \\
\hline
\end{tabular}

NCEP-ATP III National Cholesterol Education Program, Adult Treatment Panel III. IDF International Diabetes Foundation.

Abdominal Obesity $1: \geq 88 \mathrm{~cm}$.

Abdominal Obesity 2: $\geq 80 \mathrm{~cm}$

DM Diabetes Mellitus. 
Table 6 Risk Factor Set Membership from Predicted WC in ARIC Men; BMI $\leq 40$; Age $<70$. $(\mathrm{N}=3806)$

\begin{tabular}{lccccc}
\hline Risk Factor Set & $\begin{array}{l}\text { Observed proportion } \\
(\mathbf{N}) \text { in risk set }\end{array}$ & $\begin{array}{l}\text { Positive Predictive } \\
\text { Value }\end{array}$ & Sensitivity & $\begin{array}{c}\text { Specificity } \\
\text { Proportion correctly } \\
\text { predicted }\end{array}$ \\
\hline NCEP-ATP III Metabolic Syndrome & $49.8 \%(1895)$ & $94.5 \%$ & $96.9 \%$ & $94.5 \%$ & $95.7 \%$ \\
IDF Metabolic Syndrome & $58.9 \%(2242)$ & $93.8 \%$ & $94.1 \%$ & $91.1 \%$ & $92.9 \%$ \\
Abdominal Obesity 1 (AO1) & $48.8 \%(1857)$ & $83.9 \%$ & $87.4 \%$ & $84.0 \%$ & $85.7 \%$ \\
AO1 and DM & $11.9 \%(454)$ & $90.3 \%$ & $89.9 \%$ & $98.7 \%$ & $97.6 \%$ \\
AO1 and Dyslipidemia & $33.3 \%(1266)$ & $86.0 \%$ & $89.0 \%$ & $92.8 \%$ & $91.5 \%$ \\
AO1, DM and Dyslipidemia & $9.2 \%(352)$ & $90.3 \%$ & $89.8 \%$ & $99.0 \%$ & $98.2 \%$ \\
Abdominal Obesity 2 & $81.2 \%(3089)$ & $92.8 \%$ & $93.0 \%$ & $68.9 \%$ & $88.5 \%$ \\
\hline
\end{tabular}

NCEP-ATP III National Cholesterol Education Program, Adult Treatment Panel III. IDF International Diabetes Foundation.

Abdominal Obesity $1: \geq 102 \mathrm{~cm}$.

Abdominal Obesity $2: \geq 94 \mathrm{~cm}$

DM Diabetes Mellitus.

correctly identified for the abdominal obesity plus diabetes plus dyslipidemia set.

The positive predictive value (PPV) results using the predicted WC were $94.2 \%$ or higher for each of the risk factor sets. The lowest PPV was for abdominal obesity as defined by the $88 \mathrm{~cm}$ threshold alone (94.2\%), and the highest PPVs were observed for the metabolic syndrome definitions, abdominal obesity (AO) plus diabetes, and AO plus dyslipidemia plus diabetes (all above 98\%). Sensitivity using predicted WC was higher than specificity for the abdominal obesity boundaries alone and for the IDF-defined metabolic syndrome. Specificity was higher for NCEP-defined metabolic syndrome, AO plus diabetes, $\mathrm{AO}$ plus dyslipidemia, and $\mathrm{AO}$ plus diabetes plus dyslipidemia. Except for the abdominal obesity alone definitions, both sensitivity and specificity were $90.7 \%$ or higher for every risk factor set. Specificity was low (51.4\%) for the $80 \mathrm{~cm}$ abdominal obesity threshold, indicating a high number of false-positive predictions, and thus reflecting the systematic overprediction of WC among thinner women discussed above.

For men (Table 6), the proportion correctly identified as belonging to a risk factor set using the predicted WC was $91.5 \%$ or higher for all sets except abdominal obesity alone. For the higher criterion of greater than or equal to $102 \mathrm{~cm}$, the proportion correctly identified was $85.7 \%$; for the lower criterion of greater than or equal to $94 \mathrm{~cm}$, the proportion correctly identified was $88.5 \%$. Particularly for the lower $(94 \mathrm{~cm})$ threshold, the misclassified individuals were more likely to be false positives (i.e., incorrectly classified as obese) than false negatives, as indicated by specificities lower than sensitivities, and reflecting the systematic overprediction of WC among thinner men discussed above. For the risk factor sets excluding metabolic syndrome, the proportion correctly identified increased as the number of defining criteria increased, with $98.2 \%$ correctly identified for the abdominal obesity plus diabetes plus dyslipidemia set.
The positive predictive value (PPV) results using the predicted WC for men were lowest for those risk factor sets using the higher $102 \mathrm{~cm}$ threshold, ranging from $83.9 \%$ for $\mathrm{AO}$ alone to $90.3 \%$ for $\mathrm{AO}$ plus diabetes plus dyslipidemia. The highest PPVs, $93.8 \%$ and $94.5 \%$, were observed for the IDF and NCEP metabolic syndrome definitions, respectively. Sensitivity using predicted WC was higher than specificity for the metabolic syndrome risk factor sets and for the $\mathrm{AO}$ alone sets.

We also compared the results of the waist circumference prediction model to an approach using BMI threshold values to predict risk factor set membership, using the WHO-recommended BMI values to define membership in the six cardiometabolic risk factor sets. Specifically, we substituted the WHO-recommended BMI values for the waist circumference criteria as follows: $\mathrm{BMI} \geq 25 \mathrm{~kg} / \mathrm{m}^{2}$ ("overweight") corresponds to WC of $80 \mathrm{~cm}$ for women and $94 \mathrm{~cm}$ for men, and BMI $\geq 30 \mathrm{~kg} /$ $\mathrm{m}^{2}$ ("obese") corresponds to WC of $88 \mathrm{~cm}$ for women and $102 \mathrm{~cm}$ for men. Among ARIC women, the WC prediction model categorized risk factor set membership more accurately than the BMI threshold for every set. In contrast, among ARIC men the results of the two approaches differed much less. The differences in the proportions correctly identified were within one percentage point for three of the seven sets, and the WC prediction model categorized risk factor set membership more accurately than the BMI threshold in the other four sets. Tables presenting these results are available upon request.

We repeated all of the analyses described above for a simpler model omitting the race and ethnicity demographic variables. The results were essentially the same. Analogous Figures 1 and 2 (the boxplots showing the predicted WC values) and Tables 5 and 6 (the validation exercise assessing the sensitivity, specificity, positive predictive value, and proportion correctly predicted) are available upon request. 


\section{Discussion}

We constructed a model estimating WC from BMI and three demographic variables - gender, age, and race/ ethnicity - because WC is increasingly recognized as a more accurate and therefore more useful metric than BMI alone for predicting cardiometabolic risk. Using the estimated WC value from the model more accurately predicted cardiometabolic risk than using BMI alone. Because the predictor variables are generally collected in clinical practice and therefore available for assessment by practitioners as well as health plans and public health officials, this model may assist in the accurate identification of individuals at higher risk for cardiometabolic events. This would be the result even if WC is not measured and actual WC measurements are not available. As well, an alternative model is available for practitioners and researchers to whom data on race or ethnicity are not readily available.

The model is generalizable to Caucasian and AfricanAmerican adult populations because it was constructed from data in a large, population-based sample of U.S. men and women, and then validated in a population with a larger representation of African-Americans. This model has not been validated in non-Caucasian, nonAfrican-American ethnic groups. Further work in that regard should be conducted.

Although the model successfully estimates WC and, using the WC estimate, membership in the risk clusters, we observed a modest level of systematic error in the model results. Specifically, the model tends to overestimate the true $\mathrm{WC}$ in lower ranges of $\mathrm{WC}$, and underestimate the true WC in upper ranges of WC, particularly among women. Heterogeneity in the anthropometry of women (e.g., obesity in hips, thighs, and mammary tissue not measured by WC) compared with men likely accounts for the greater mean differences in the predicted and observed WC values for women as compared with men. Efforts to identify a correction term in the model for the NHANES data were unsuccessful. However, the magnitude of the systematic error is sufficiently small that using the estimated WC to identify cardiometabolic risk is accurate in both genders, and slightly better for women.

\section{Conclusions}

The model accurately estimates WC and identifies cardiometabolic risk. It should be useful for health care practitioners and public health officials who wish to identify individuals and populations at risk for cardiometabolic disease when WC data are unavailable.

\section{Competing interests}

The majority of the work overall, including this manuscript, has not been performed with sponsorship funding. Initial aspects of this work were sponsored by Sanofi-Aventis, which funded Abt Bio-Pharma Solutions, a subsidiary of Abt Associates, Inc., to lead this study. In that initial stage, SRB performed the research as an employee of Abt Associates; DCH, TMB and CLP performed this study as employees of Abt Bio-Pharma Solutions, now part of United BioSource Corporation; RHBJ contributed as an employee of Sanofi-Aventis; and CSH contributed as an employee of Pennsylvania State University.

\section{Authors' contributions}

All authors made substantive intellectual contributions to this study. SRB and DCH contributed to study design and analysis; drafted the initial version of the manuscript; and contributed to its critical revision. SRB, TMB and CLP contributed to data acquisition. TMB, CLP, RHBJ and CSH also contributed to the study design, analysis, and critical revision of the manuscript for important intellectual content. Each author has participated sufficiently in the work to take public responsibility for manuscript content, and has read and approved the final manuscript.

\section{Acknowledgements}

Initial aspects of the research presented in this paper were sponsored by Sanofi-Aventis.

\section{Author details}

${ }^{1}$ Abt Associates Inc., Cambridge, MA, USA. ${ }^{2}$ Independent consultant, Sudbury, MA, USA. ${ }^{3}$ Optumlnsight, Waltham, MA, USA. ${ }^{4}$ United BioSource Corporation, Lexington, MA, USA. ${ }^{5}$ Purdue Pharma L.P., Stamford, CT, USA. ${ }^{6}$ Penn State College of Medicine, Department of Surgery, Hershey, PA, USA.

Received: 21 June 2011 Accepted: 11 July 2012

Published: 3 August 2012

\section{References}

1. National Heart, Lung, and Blood Institute: Clinical Guidelines on the Identification, Evaluation, and Treatment of Overweight and Obesity in Adults: The Evidence Report. Bethesda, MD: National Heart, Lung, and Blood Institute; 1998.

2. World Health Organization Consultation on Obesity: Obesity: Preventing and Managing the Global Epidemic. Geneva, Switzerland: Division of Noncommunicable Diseases, Programme of Nutrition, Family and Reproductive Health, World Health Organization; 1998.

3. Hu FB: Obesity and mortality: watch your waist, not just your weight. Arch Intern Med 2007, 167(9):875-876.

4. Wang Y, Rimm EB, Stampfer MJ, Willett WC, Hu FB: Comparison of abdominal adiposity and overall obesity in predicting risk of type 2 diabetes among men. Am J Clin Nutr 2005, 81(3):555-563.

5. Despres JP, Lemieux I: Abdominal obesity and metabolic syndrome. Nature 2006, 444(7121):881-887.

6. Pouliot MC, Despres JP, Nadeau A, Moorjani S, Prud'Homme D, Lupien PJ, Tremblay A, Bouchard C: Visceral obesity in men. Associations with glucose tolerance, plasma insulin, and lipoprotein levels. Diabetes 1992, 41(7):826-834

7. Snijder MB, van Dam RM, Visser M, Seidell JC: What aspects of body fat are particularly hazardous and how do we measure them? Int J Epidemiol 2006, 35(1):83-92.

8. Rankinen T, Kim SY, Perusse L, Despres JP, Bouchard C: The prediction of abdominal visceral fat level from body composition and anthropometry: ROC analysis. Int J Obes Relat Metab Disord 1999, 23(8):801-809.

9. Zhu S, Wang Z, Heshka S, Heo M, Faith MS, Heymsfield SB: Waist circumference and obesity-associated risk factors among whites in the third National Health and Nutrition Examination Survey: clinical action thresholds. Am J Clin Nutr 2002, 76(4):743-749.

10. Ford ES: Prevalence of the metabolic syndrome defined by the International Diabetes Federation among adults in the U.S. Diabetes Care 2005, 28(11):2745-2749.

11. Hollenbeak CS, Spackman DE, Ben-Joseph RH, Okamoto LJ, Luce BR, Schwartz JS, Sullivan SD: Predicting clusters of cardiometabolic risk when clinical data are limited. Value Health 2007, 10(s1):S4-S11.

12. Scranton RE, Bozeman SR, Burton TM, Hoaglin DC, Sirko S, Hollenbeak CS, Wilson PWF: Simple demographic model to predict multiple cardiometabolic risk factors in two well-known observational cohorts. Value Health 2007, 10(s1):S37-S44 
13. Centers for Disease Control and Prevention (CDC) and National Center for Health Statistics (NCHS): National Health and Nutrition Examination Survey Data. Hyattsville, MD: U.S. Department of Health and Human Services, Centers for Disease Control and Prevention; 2003.

14. The ARIC investigators: The Atherosclerosis Risk in Communities (ARIC) Study: design and objectives. Am J Epidemiol 1989, 129(4):687-702.

doi:10.1186/1471-2288-12-115

Cite this article as: Bozeman et al.: Predicting waist circumference from body mass index. BMC Medical Research Methodology 2012 12:115.

\section{Submit your next manuscript to BioMed Central} and take full advantage of:

- Convenient online submission

- Thorough peer review

- No space constraints or color figure charges

- Immediate publication on acceptance

- Inclusion in PubMed, CAS, Scopus and Google Scholar

- Research which is freely available for redistribution 